\title{
MBARU NIANG DALAM PERSPEKTIF ETNOMATEMATIKA DI KAMPUNG RUTENG PU'U
}

\author{
Melita M. Muliani, Alberta P. Makur, Valeria S. Kurnila, Inosensius Sutam \\ Universitas Katolik Indonesia Santu Paulus Ruteng, Jl. Ahmad Yani No. 10, Ruteng, Indonesia \\ E-mail: alberta_makur@unikastpaulus.ac.id
}

\begin{abstract}
Abstrak
Penelitian ini bertujuan untuk mengungkap bagaimana masyarakat Manggarai menggunakan konsep matematika dalam pembuatan atap rumah adat Manggarai dan apa saja konsep matematika yang terdapat dalam atap rumah adat Manggarai. Model peneliatian ini menggunakan pendekatan kualitatif dengan metode Etnografi. Pemilihan subjek dalam penelitian ini menggunakan teknik purposive sampling. Keabsahan data diperoleh melalui reliabilitas data juga melalui reliabilitas pendukung lainnya seperti teori dan fakta di lapangan juga melalui expert judgement sebagai orang yang mengakui keabsahan data penelitian ini. Hasil penelitian menunjukkan bahwa dalam pembuatan rumah adat Manggarai terdapat 3 aktivitas matematika yang dilakukan yaitu mendesain, menghitung, dan mengukur. Selain itu, konsep matematika yang terdapat dalam rumah adat Manggarai yaitu konsep bangun datar yang terdiri dari bangun datar segitiga, trapesium serta lingkaran, konsep jarak, konsep sejajar, berpotongan, dan saling tegak lurus serta konsep bangun ruang (limas).
\end{abstract}

Kata kunci: Etnomatematika, Rumah Adat Manggarai, Mbaru Niang

\begin{abstract}
This study aimed to reveal how the Manggarai community used mathematical concepts in making the traditional house (Mbaru Niang) roof of Manggarai people and what were the mathematical concepts contained in it. This research used a qualitative approach with ethnographic methods. The selection of subjects in this study used purposive sampling technique. Data obtained by interviewing, observing and documenting. The validity of the data is supported through theory and facts in the field and also through expert judgment. The results showed that in the stages of the process of making the traditional house roof of Manggarai there were 3 activities that had a mathematical nuance namely designing, numerating and measuring and the mathematical concepts contained in the traditional house roof were the concept of the shapes namely triangles, rectangles, trapezoid and circles, the concept of distance, the concept of parallel lines, and lines and the pyramid.
\end{abstract}

Keywords: Ethnomathematics, Manggarai Traditional House, Mbaru Niang

\section{PENDAHULUAN}

Matematika awalnya dikembangkan oleh masyarakat untuk keperluan hidupnya yang akhirnya berkembang dan kemudian dipelajari di sekolah (Barton, 1996; Safitri, 2015; Aikpitanyi \& Eraikhuemen, 2017). Oleh karena itu perkembangan matematika tidak terlepas dari perkembangan budaya manusia. Aikpitanyi dan Eraikhuemen (2017) menyatakan bahwa pendekatan budaya terbukti sebagai salah satu strategi pembelajaran 
yang efektif untuk memaksimalkan hasil belajar siswa. Hal ini ditegaskan oleh Barton (1996) yang menyatakan bahwa matematika menjadi bermakna hanya jika diintegrasikan dengan budaya, dan bahwa pandangan tidak hanya berlaku untuk pendidikan matematika melainkan juga matematika secara umum.

Ezeife (2002) dalam penelitiannya terkait Suku Aborigin di Australia menuliskan pendekatan pengajaran dan pembelajaran matematika dari sudut pandang budaya bertujuan menghubungkan pengetahuan latar belakang siswa, dan pengajaran dan pembelajaran matematika formal yang siswa akan temui di sekolah. Jika tujuan ini tercapai maka pembelajaran matematika menjadi dekat dengan tradisi dan budaya yang sudah berakar dan memainkan peran penting dalam kehidupan anak-anak muda. Mempelajari matematika dalam konteks budaya dimaksudkan untuk menanamkan kepedulian terhadap budaya, membuat generasi yang berpendidikan dan lebih muda sadar bahwa mereka ingin melestarikan dan mengembangkan nilai-nilai budaya, dan menyadari bahwa budaya adalah tempat utama dan pertama untuk membentuk karakter dan kepribadian seseorang (Makur et al., 2019). Hal ini didukung oleh penelitian terhadap kerajinan anyaman Bali yang dilakukan Puspadewi dan Putra (2014) menunjukkan bahwa budaya dapat dimanfaatkan sebagai sumber belajar dalam pembelajaran, menambah wawasan siswa mengenai keberadaan matematika yang ada pada salah satu unsur budaya yang mereka miliki, meningkatkan motivasi dalam belajar serta memfasilitasi siswa dalam mengaitkan konsep-konsep yang dipelajari dengan situasi dunia nyata.

Secara khusus dalam kaitannya dengan pendidikan matematika, hubungan antara matematika dan budaya penting untuk dipelajari karena budaya dapat menjadi jembatan antara kehidupan nyata dan abstraksi dalam matematika. Hubungan antara matematika dan budaya, menurut para ahli, dikenal sebagai etnomatematika (Abdullah, 2017; Biembengut, 2016; Rosa \& Orey, 2013). Etnomatematika adalah bentuk penurunan ideide matematika yang dibuat untuk menjelaskan praktik-praktik matematika melalui perilaku yang diterapkan dalam budaya (Indrawati, 2015). Matematika pun secara luas dianggap sebagai salah satu mata pelajaran yang paling penting dalam kurikulum sekolah seperti tertera dalam standar isi. Matematika memberikan pengetahuan dan keterampilan sederhana yang dibutuhkan oleh seorang individu dalam menangani masalah kehidupan sehari-hari. Indrawati (2015) menjelaskan bahwa pandangan yang menyebutkan matematika tidak memiliki kaitan dengan budaya mulai dirasakan sebagai pandangan 
yang keliru.

Matematika merupakan abstraksi pikiran manusia, digunakan sebagai alat untuk pemecahan masalah. Namun demikian, matematika selalu dianggap sulit oleh siswa pada umumnya, salah satu alasannya adalah tidak konsistennya pendidik dalam memberikan pembelajaran di sekolah, yang tidak dapat mengambil keuntungan dari lingkungan lokal. Oleh karena itu sangat penting agar konsep-konsep matematika yang terdapat dalam kebudayaan-kebudayaan saat ini digali agar konsep-konsep tersebut dapat membantu siswa dalam mempelajari matematika di sekolah. Pelaksanaan kegiatan pembelajaran di sekolah diharapkan dapat disesuaikan dengan konteks budaya peserta didik agar matematika dapat lebih mudah dipahami karena tidak lagi dipersepsikan sebagai sesuatu yang asing dan sulit oleh peserta didik dan masyarakat. Masyarakat sering tidak menyadari bahwa mereka telah menerapkan berbagai konsep matematika dalam adat istiadat dan budaya mereka seperti mengukur, menghitung dan lain sebagainya. Salah satu ranah kajian yang mengaitkan antara matematika dan budaya adalah etnomatematika.

Etnomatematika berasal dari tiga kata yaitu: ethnos yang berarti dalam lingkungan budaya; mathema yang berarti sesuatu yang berkaitan dengan matematika; dan tics yang berarti teknik berhitung (Safitri, 2015). D’Ambrosio (1985) menegaskan pula bahwa etnomatematika adalah kajian yang berkaitan dengan matematika, yang memperhitungkan budaya dimana matematika muncul dengan memahami penalaran dan sistem matematika yang mereka gunakan. Puspadewi dan Putra (2014) mengatakan etnomatematika merupakan matematika yang tumbuh dan berkembang dalam suatu kebudayaan tertentu. Melalui etnomatematika kita dapat memandang dan memahami matematika sebagai produk budaya. Etnomatematika merupakan bagian dari matematika yang menjadi jembatan atau sarana yang dapat menghubungkan matematika yang formal dengan matematika yang ada dalam kehidupan sehari-hari. Hal ini didukung oleh penelitian yang dilakukan Fujiati dan Mastur (2014 menunjukkan bahwa pembelajaran matematika yang berbasis etnomatematika lebih bersifat kontesktual serta mampu menumbuhkan rasa cinta pada budaya.

Matematika secara luas dianggap sebagai salah satu mata pelajaran yang paling penting dalam kurikulum sekolah seperti tertera dalam standar isi. Matematika memberikan pengetahuan dan keterampilan sederhana yang dibutuhkan oleh seorang individu dalam menangani masalah kehidupan sehari-hari. Indrawati (2015) menjelaskan 
bahwa pandangan yang menyebutkan matematika tidak memiliki kaitan dengan budaya mulai dirasakan sebagai pandangan yang keliru. Matematika merupakan abstraksi pikiran manusia, digunakan sebagai alat untuk pemecahan masalah.

Namun demikian, matematika selalu dianggap sulit oleh siswa pada umumnya, salah satu alasannya adalah tidak konsistennya pendidik dalam memberikan pembelajaran di sekolah, yang tidak dapat mengambil keuntungan dari lingkungan lokal. Oleh karena itu sangat penting agar konsep-konsep matematika yang terdapat dalam kebudayaan-kebudayaan saat ini digali agar konsep-konsep tersebut dapat membantu siswa dalam mempelajari matematika di sekolah. Pelaksanaan kegiatan pembelajaran di sekolah diharapkan dapat disesuaikan dengan konteks budaya peserta didik agar matematika dapat lebih mudah dipahami karena tidak lagi dipersepsikan sebagai sesuatu yang asing dan sulit oleh peserta didik dan masyarakat. Masyarakat sering tidak menyadari bahwa mereka telah menerapkan berbagai konsep matematika dalam adat istiadat dan budaya mereka seperti mengukur, menghitung dan lain sebagainya. Salah satu ranah kajian yang mengaitkan antara matematika dan budaya adalah etnomatematika.

Seiring berkembangnya teknologi dan ilmu pengetahuan, budaya mulai hilang eksistensinya dan bahkan punah karena tidak ada generasi yang bisa mewariskan kebudayaan tersebut. Demikian pun halnya dengan kehidupan budaya dan adat istiadat masyarakat Manggarai, dengan berkurangnya pengetahuan generasi muda tentang budaya Manggarai maka lambat laun budaya Manggarai akan kehilangan eksistensinya. Salah satu warisan budaya Manggarai yang diturunkan oleh nenek moyang hingga saat ini adalah rumah adat Manggarai.

Rumah adat Manggarai (mbaru niang) berbentuk menyerupaikerucut, bersegi lima yang terdiri atas tiga bagian utama yakni ngaung (bagian bawah rumah yang memiliki kolong), batéka'éng (tempat kediaman manusia) dan wuwung (atap) (Deki, 2011). Rumah adat Manggarai memiliki bentuk yang unik dan menarik. Pada budaya Manggarai, belum ada landasan ilmiah yang tertulis yang menunjukkan setiap pengetahuan dan kegiatan yang dilakukan oleh masyarakat Manggarai didasari oleh ilmu matematika dan ilmu pengetahuan modern. Masyarakat hanya mengetahui pengetahuan tentang budaya khususnya pada rumah adat Manggarai, sebagai pengetahuan turun temurun dan belum dianggap penting untuk diketahui. Guru pun tidak memanfaatkan budaya sebagai sarana untuk membantu siswa dalam memahami materi pembelajaran karena ketika suatu materi 
begitu jauh dari skema budaya yang mereka miliki tentunya materi tersebut akan menjadi sulit dipahami.

Penelitian ini bertujuan untuk mengkaji aspek-aspek dalam rumah adat Manggarai dalam perspektif matematika dengan berfokus pada bentuk atap rumah adat Manggarai (mbaru niang) yang berbentuk kerucut atau limas. Penelitian ini juga dapat menjadi bahan rujukan pembelajaran matematika kontekstual dan dasar pengembangan bahan pembelajaran matematika kontekstual berbasis unsur lokal yang memperhatikan lingkungan sosial budaya masyarakat dan kearifan lokal. Dengan demikian siswa tidak merasa asing dan dapat dengan mudah memahami konsep bangun ruang (limas) dan bangun datar karena mereka sudah menjumpai dan kenal dengan benda yang berbentuk serupa. Dengan demikian masyarakat dan peserta didik memperoleh informasi baru bahwa rumah adat Manggarai memiliki kaitan erat dengan matematika, sehingga mereka lebih memahami keterkaitan antara matematika dan budaya yang mereka miliki.

Berdasarkan paparan di atas peneliti tertarik untuk meneliti rumah adat Manggarai yang berada di Kampung Ruteng Pu'u, maka peneliti mengangkat masalah tersebut melalui penelitian yang berjudul "Mbaru Niang dalam Perspektif Etnomatematika di Kampung Ruteng Pu'u'. Fokus penelitian yaitu Rumah adat Manggarai dilihat dari perspektif matematika berdasarkan rumah adat (Mbaru Niang Gendang dan Mbaru Niang Tambor) di Kampung Ruteng Pu'u dengan subfokus penelitian yaitu konsep matematika yang terkandung dalam bentuk atap rumah adat Manggarai (Mbaru Niang Gendang dan Mbaru Niang Tambor) di Kampung Ruteng Pu'u dengan rumusan masalah (1) Aktivitas matematika yang dilakukan masyarakat Manggarai dalam proses pembuatan atap rumah adat Manggarai (Mbaru Niang Gendang dan Mbaru NiangTambor) di Kampung Ruteng Pu'u?; (2) Apa saja konsep matematika yang terkandung dalam atap rumah adat Manggarai (Mbaru Niang Gendang dan Mbaru Niang Tambor) di Kampung Ruteng Pu'u?

\section{METODE PENELITIAN}

Metode dalam penelitian ini menggunakan pendekatan kualitatif. Gall et al., (2007) menyatakan bahwa penelitian kualitatif adalah penelitian yang menggunakan latar alamiah, dengan maksud menafsirkan fenomena yang terjadi dan dilakukan dengan jalan melibatkan berbagai metode yang ada. Dalam penelitian kualitatif metode yang biasanya 
dimanfaatkan adalah observasi, wawancara, dan dokumentasi. Metode yang digunakan adalah metode etnografi. Metode etnografi (Achor et al., 2009) adalah penelitian untuk mendeskripsikan kebudayaan sebagaimana adanya.

Metode ini berupaya mempelajari peristiwa kultural yang menyajikan pandangan hidup subjek sebagai objek studi. Melalui etnogafi, peneliti dapat menginformasikan teori-teori ikatan budaya, memahami mayarakat yang kompleks, memahami perilaku manusia dan menemukan teori berdasarkan data (D'Ambrosio, 2001). Data lapangan dalam penelitian ini merupakan konsep Matematika apa saja yang terdapat dalam rumah adat Manggarai lebih khusus atap dari rumah adat Manggarai.

Pemilihan subyek menggunakan teknik purposive sampling yaitu penentuan sampel berdasarkan pertimbangan tertentu diantaranya dilihat dari pengetahuan dan pemahaman subyek sesuai masalah yang akan diteliti, profesi dan peran dalam masyarakat karena secara langsung berurusan dengan topic bahasan yang akan diteliti oleh peneliti.

Pengumpulan data dilakukan dengan menggunakan teknik wawancara, observasi dan dokumentasi, sedangkan analisis data dilakukan sejak awal peneliti terjun kelokasi penelitian hingga pada akhir penelitian. Analisis data dalam penelitian ini meliputi reduksi data, penyajian data dan penarikan kesimpulan. Keabsahan data diperoleh melalui reliabilitas data juga melalui reliabilitas pendukung lainnya seperti teori dan fakta di lapangan juga melalui expert judgement sebagai orang yang mengakui keabsahan data penelitian ini.

\section{HASIL DAN PEMBAHASAN}

Penelitian dilaksanakan di kampung Ruteng Pu'u, Kecamatan Langke Rembong, Kabupaten Manggarai Propinsi Nusa Tenggara Timur. Kampung Ruteng Pu'u merupakan kampung dengan rumah adat tertua di Manggarai. Kampung Ruteng Pu'u sebagai kampung dengan rumah adat tertua di Manggarai menjadi salah satu tempat pariwisata yang sering dikunjungi oleh tamu asing maupun tamu lokal. Kampung Ruteng Pu'u menjadi obyek wisata karena keaslian dan nilai budaya dari rumah adatnya tetap terjaga sejak pertama kali dibuat hingga sekarang, seperti tampak pada Gambar 1. 


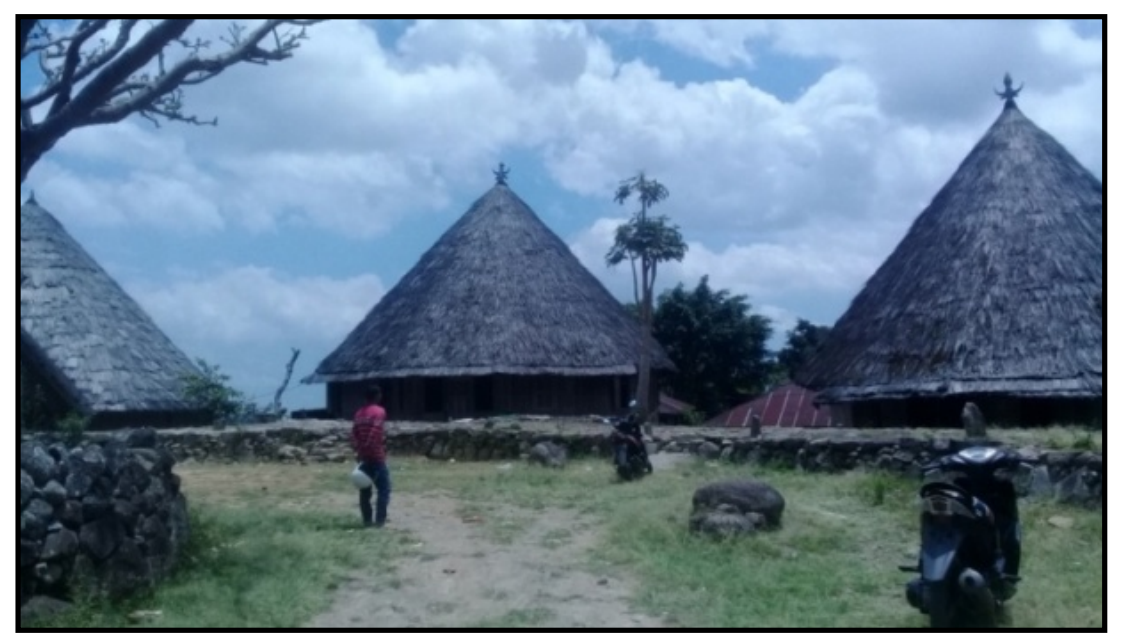

Gambar 1. Mbaru Niang Ruteng Pu'u

Mbaru niang merupakan salah satu syarat terbentuknya sebuah kampung. Mbaru niang dibuat karena berkembangnya cara pikir manusia yang awalnya berlindung diri dalam gua hingga membuat tempat tinggal yang menetap. Pada umumnya rumah adat yang dibangun memiliki kolong yang berfungsi untuk menghindari serangan hewan buas. Dinding mbaru niang terbuat dari papan yang digergaji secara manual. Atap mbaru niang dari ijuk karena tahan lama dan cukup kuat. Berikut ini akan diurakan bagian-bagian dari rumah adat Manggarai.

1. Ngaung (kolong) yaitu bagian bawah mbaru niang tepatnya dibawah lutur yang berfungsi sebagai tempat memelihara hewan peliharaan seperti babi, kambing dan ayam, seperti tampak pada Gambar 2.

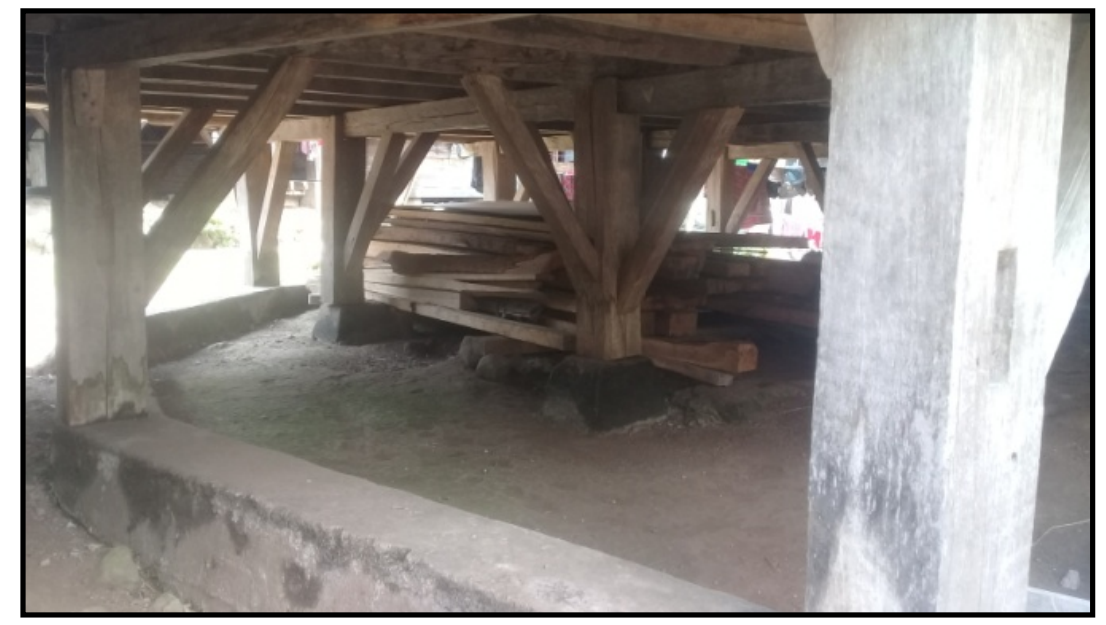

Gambar 2. Ngaung mbaru niang

2. Baté ka'éng (tempat kediaman manusia) yaitu tempat di mana manusia beraktivitas.

Pada baté ka'éng terdapat lutur tempat manusia melakukan upacara-upacara adat, 
tempat untuk melakukan musyawarah bagi kepentingan desa serta tempat untuk menerima tamu dan juga loang tempat untuk manusia tidur, seperti yang terlihat pada Gambar 3.

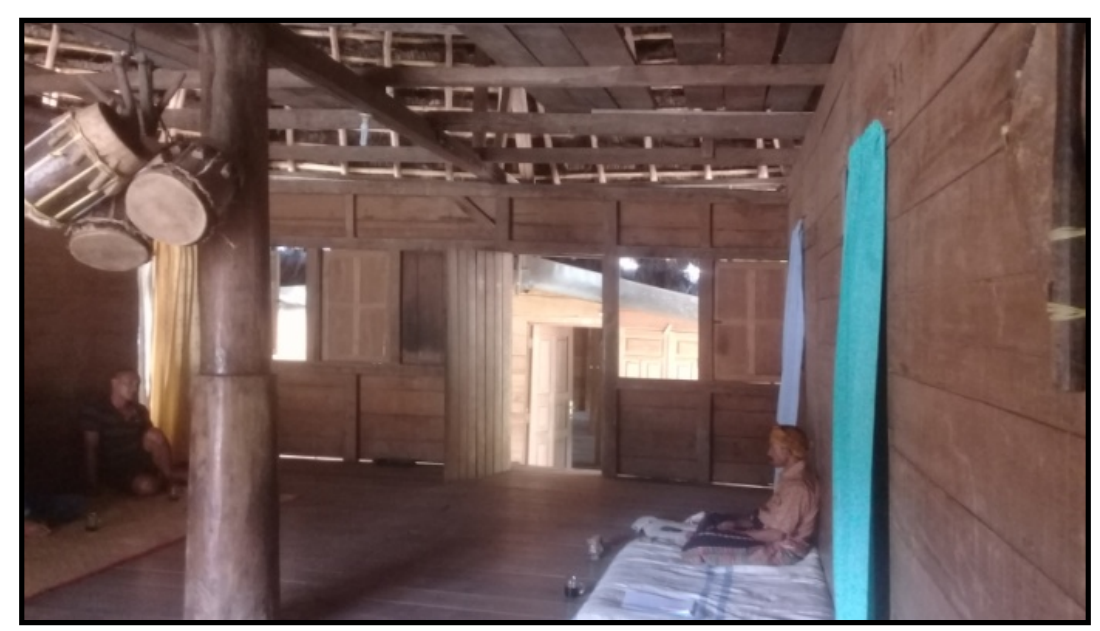

Gambar 3. Bate ka'eng mbaru niang

3. Léba (lobo) mésé yaitu loteng yang terdapat pada bagian dalam atap mbaru niang yang berfungsi sebagai tempat menyimpan cadangan makanan seperti padi, jagung dll.

4. Léba (lobo) lempa raé yaitu loteng tingkat kedua pada bagian dalam atap mbaru niang yang befungsi sebagai tempat menyimpan benih padi, benih jagung dll.

5. Léba (lobo) ruang koé yaitu loteng tingkat ke tiga pada bagian dalam atap mbaru niang yang berfungsi sebagai tempat menyimpan barang-barang pusaka peninggalan nenek moyang. Pada zaman dahulu ketika terjadi perang, léba ruang koé dijadikan sebagai tempat persembunyian bagi anak-anak.

6. Léba (lobo) sékang kodé yaitu loteng tingkat keempat pada bagian dalam atap mbaru niang yang berfungsi sebagai tempat menyimpan air dalam botol yang dapat menghindari terjadinya kebakaran dalam suatu kampung.

Mbaru niang berbentuk bulat dengan atap yang mengerucut merupakan simbol dan gambaran cara hidup masyarakat Manggarai yang memegang teguh persatuan. Mbaru niang berbentuk bulat melambangkan masyarakat Manggarai yang selalu berkumpul dalam forum lonto léok (duduk melingkar) untuk merundingkan sesuatu hal dalam mencapai musyawarah yang mufakat. Pernyataan di atas dibenarkan dengan bukti kutipan wawancara yaitu sebagai berikut ( $\mathrm{P}=\mathrm{Peneliti}$ dan $\mathrm{N}=$ Narasumber). 
$P \quad: \quad$ Bagaimana cara orang tua zaman dulu dalam membangun mbaru niang sehingga seperti bentuk sekarang ini ema?

$N$ : Pertama mereka menentukan titik pusat mbaru niang yang akan menjadi tempat untuk memasang siri bongkok, dengan menggunakan tali dan kayu mereka membuat batas luar yang menentukan besarnya ukuran mbaru niang itu nantinya. Mereka membuat rumah adat berbentuk bulat karena mereka ingin meniru kebiasaan mereka sehari-hari yang selalu mendiskusikan sesuatu hal dalam forum lonto léok.

Satuan ukur yang digunakan orang jaman dahulu menggunakan satuan yang tidak baku yaitu mengukur menggunakan tangan, pagat setara dengan $\pm 20 \mathrm{~cm}$, ciku setara dengan $\pm 50 \mathrm{~cm}$ dan depa setara dengan $\pm 2 \mathrm{~m}$. Informasi tersebut dibuktikan pada cuplikan wawancara berikut.

$P$ : Apakah mereka mengukur jaraknya ema, bagaimana cara mereka mengukur?

$N$ : $\quad$ Ia enu, mereka ukur dengan menggunakan tangan. Dulu biasanya mereka mengukur dengan satuan pagat, ciku dan depa. Pagat itu kira-kira kalau dibawa ke satuan cm sama dengan \pm $20 \mathrm{~cm}$, ciku sama dengan $\pm 50 \mathrm{~cm}$ dan depa sama dengan \pm 2 meter.

Mbaru niang terdiri dari 5 tingkat, tingkat pertama yaitu lutur (tempat manusia tinggal), tingkat ke dua yaitu léba mésé tempat menyimpan bahan cadangan makanan seperti padi, jagung dan lai-lain. Tingkat yang ke tiga yaitu léba lempa raé tempat menyimpan benih padi, benih jagung dan menyimpan larik dan nggilu (peralatan caci), tingkat yang ke empat yaitu léba ruang koé yaitu tempat menyimpan barang pusaka peninggalan nenek moyang dan tingkat yang ke lima léba sékang kodé. Pernyataan di atas dibuktikan dengan cuplikan wawancara berikut.

$P: \quad$ Sebenarnya mbaru niang ini terbagi menjadi berapa bagian ema 3 atau 5 bagian?

$N$ : Mbaru niang jika dihitung dari kolongnya terdapat 6 bagian, tetapi jika kita menyebutnya dengan kata tingkat maka dihitung dari tempat kediaman manusia rumah adat punya 5 tingkat yaitu tempat kediaman manusia (lutur), léba mésé, léba lempa raé, léba ruang koé dan léba sékang kodé. Dari 6 bagian itu enu sudah punya fungsinya masing-masing. Ngaung untuk menyimpan babi, ayam dan kambing. Lutur untuk tempat kediaman manusia, léba mésé untuk menyimpan bahan makanan 
(padi, jagung), léba lempa raé untuk menyimpan benih padi dan larik agu nggilu (peralatan caci). Di léba ruang koé enu untuk menyimpan barang-barang magic sebagai sumber kekuatan warga kampung jika ada orang yang ingin merampas kampung. Di léba sékang kodé untuk menyimpan air dan orang tua jaman dulu menyimpanya dalam robo agar tidak terjadi kebakaran dalam kampung.

Atap mbaru niang menggunakan ijuk karena ijuk tergolong kuat untuk dijadikan atap juga tahan lama. Ijuk memiliki panjang bervariasi dan paling panjang 6 pagat dengan lebar 3 sampai 5 pagat.

$P$ : Mengapa atap mbaru niang menggunakan ijuk?

$N$ : Atap mbaru niang menggunakan ijuk karena ijuk sangat kuat, tahan air dan tahan panas walaupun melewati berapa musim ijuk tetap utuh.

$P: \quad$ Berapa ukuran dari ijuk ema?

$N$ : $\quad$ Panjang ijuk paling panjang bisa mencapai 6 pagat dan ada yang kurang dari itu. Lebarnya sekitar 3 sampai 5 pagat

Kehidupan nyata berupa lingkungan sekitar siswa yang meliputi lingkungan sosial dan budaya merupakan media kontekstual yang membantu siswa menemukan konsep dan mengaitkankannya dengan konsep matematika yang dipelajari (Mumu \& Aninam, 2018). Berdasarkan hasil penelitian, peneliti dapat mengkategorikan beberapa unsur matematika dan budaya yang terkandung dalam lingkungan budaya siswa khususnya Atap rumah adat Manggarai yang dapat dimanfaatkan sebagai jembatan untuk mempelajari konsep matematika.

1. Aktivitas matematika dalam pembuatan atap rumah adat Manggarai.

a. Mendesain

Nenek moyang jaman dahulu memiliki alasan khusus dalam mendesain bentuk atap rumah adat Manggarai untuk pertama kalinya. Rumah adat didirikan karena rumah adat merupakan pusat dari segala kegiatan masyarakat dalam suatu kampung. Alas atap rumah adat (mbaru niang) berbentuk lingkaran melambangkan masyarakat yang duduk bersama membentuk lingkaran dalam merundingkan sesuatu, sedangkan ujung atas atap tempat bersatunya semua kayu yang membentuk jaring-jaring atap melambangkan masyarakat Manggarai yang selalu seia sekata dan sehati sejiwa.

Dalam mendesain bentuk rumah adat yang berbentuk lingkaran. Terlebih dahulu 
mereka menentukan titik sentral yang akan menjadi tempat berdirinya siri bongkok. Dari titik sentral tersebut kemudian mereka menggunakan tali yang melalui titik sentral tersebut hingga ke tepi sesuai dengan besar rumah adat yang hendak dibangun. Tali yang digunakan memiliki panjang yang sama dari titik sentral rumah adat sehingga setelah beberapa tali di tarik melalui titik sentral hingga ke tepi maka didapat bentuk bulat pada rumah adat. Bagian dalam atap rumah adat juga dirancang sedemikian rupa yaitu memiliki loteng yang disebut léba yang bertingkat 4 yang memiliki fungsinya masingmasing. Tingkat pertama yang disebut léba mésé berfungsi untuk menyimpan bahan makanan seperti padi, jagung dll. Tingkat kedua yaitu léba lempa raé yang berfungsi untuk menyimpat bibit padi dan bibit jagung, tingkat ketiga berfungsi untuk menyimpan semua benda keramat dan benda-banda antik dalam suatu kampung dan tingkat yang ke empat disebut léba sékang kodé untuk menyimpan air dalam sebuah wadah yang berfungsi untuk melindungi seluruh kampung agar tidak dapat terjadi kebakaran dalam kampung tersebut.

\section{b. Mengukur}

Pengukuran dalam pembuatan atap rumah adat Manggarai menggunakan pengukuran tradisional. Teknik mengukur yang digunakan orang jaman dulu yaitu dengan menggunakan anggota badan seperti tangan dalam istilah bahasa Manggarai pagat, ciku dan depa. Dalam menentukan titik sentral rumah, mengukur panjang kayu sebagai bahan bangunan untuk membuat jaring-jaring atap rumah adat dan mengukur ijuk yang digunakan sebagai atap rumah adat semua dilakukan dengan pengukuran tradisional.

Tabel 1. Pengukuran Tradisional Masyarakat Manggarai

\begin{tabular}{lll}
\hline $\begin{array}{c}\text { Ukuran } \\
\text { Tradisional }\end{array}$ & \multicolumn{1}{c}{ Deskripsi Ukuran } & \multicolumn{1}{c}{ Kesetaraan } \\
\hline Pagat & $\begin{array}{l}\text { Ukuran telapak tangan orang dewasa yang } \\
\text { direntangkan. Diukur dari ujung jari tengah }\end{array}$ & $\begin{array}{l}\text { Satu pagat setara } \\
\text { dengan } \pm 20 \mathrm{~cm}\end{array}$ \\
& $\begin{array}{l}\text { Sampai ibu jari. } \\
\text { Ciku }\end{array}$ & Ukuran dari ujung jari tengah sampai siku \\
Depa & $\begin{array}{l}\text { Satu ciku setara } \\
\text { dengan } \pm 50 \mathrm{~cm}\end{array}$ \\
& $\begin{array}{l}\text { Ukuran dari ujung jari tengah salah satu } \\
\text { lengan orang dewasa hingga ujung jari } \\
\text { tengah lengan lainnya }\end{array}$ & $\begin{array}{l}\text { Satu depa setara } \\
\text { dengan } \pm 2 \mathrm{~m}\end{array}$ \\
\hline
\end{tabular}

c. Membilang

Masyarakat jaman dahulu menggunakan bilangan untuk menghitung ukuran bahan 
bangunan yang akan digunakan dalam pembuatan rumah adat Manggarai. Masyarakat Manggarai membilang ditunjukkan dengan pertanyaan pisa léwéd, pisa ngéngga yang digunakan dalam proses membangun mbaru niang. Wunut ukuran biasanya memiliki panjang \pm 6 pagat dengan lebar satu ijuk \pm 3 atau 5 pagat.

2. Konsep matematika yang terkandung dalam atap rumah adat Manggarai dengan Implementasinya Dalam Topik Pembelajaran Matematika Kurikulum 2013 adalah sebagai berikut:

a. Konsep bangun datar

Konsep bangun datar yang terbentuk dari atap mbaru niang terlihat pada penampakkan bagian dalam atap mbaru niang yang terbentuk dari perpotongan kayukayu sebagai kerangka dari atap mbaru niang yaitu segitiga, lingkaran, dan trapesium. KD yang terkait dengan konsep bangun datar yang terbentuk dari konstruksi atap mbaru niang yaitu SD kelas I KD 3.6 Mengenal bangun ruang dan bangun datar dengan menggunakan berbagai benda konkret. Perpotongan dua buah tonggor dengan salah satu ujung yang menyatu dan sebuah gélak wéngké léok menghasilkan sebuah bidang yang menyerupai segitiga seperti pada Gambar 4.

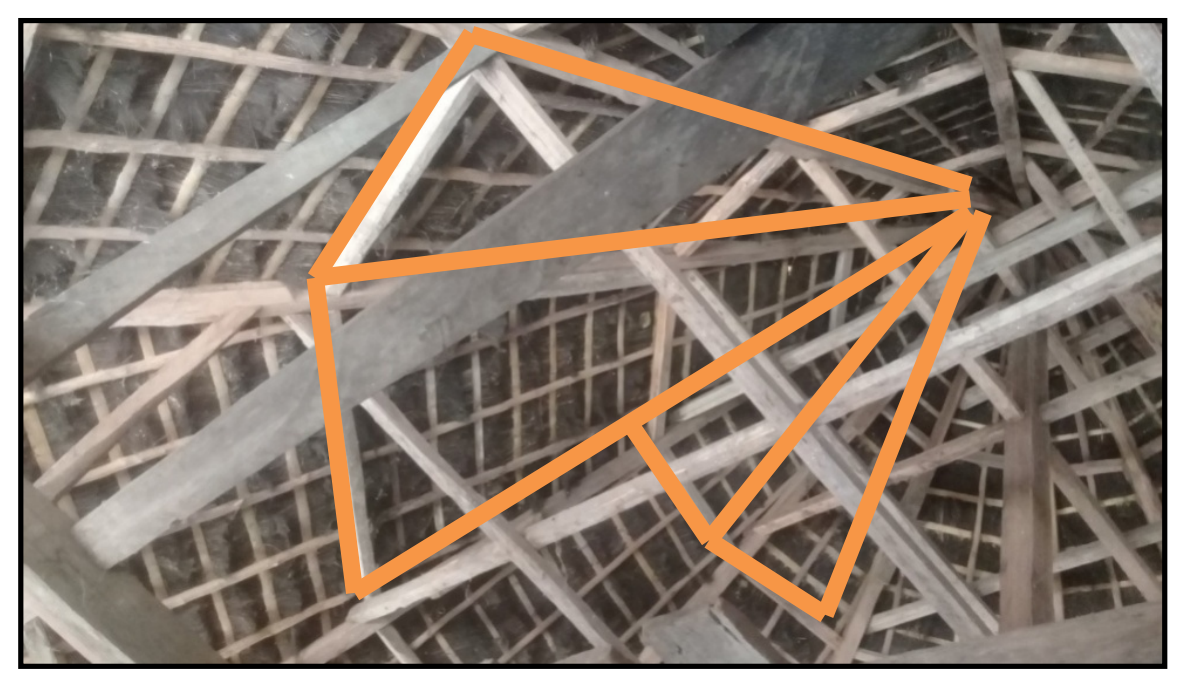

Gambar 4. Jaring atap mbaru niang yang menyerupai segitiga

Berdasarkan penelitian, bentuk alas atap rumah adat menyerupai lingkaran dan bagian dalam atap mbaru niang terdapat empat loteng (léba) yaitu léba mésé, léba lempa raé, léba ruang koé dan léba sékang kodé. Selain alas atap rumah adat berbentuk 
lingkaran. Léba pada atap mbaru niang menyerupai lingkaran dengan titik pusat titik yang dilalui siri wuwung. Atap rumah adat berbentuk kerucut, dengan loteng D,C,B berbentuk kerucut terpancung, dan loteng A berbentuk kerucut, seperti tampak pada Gambar 5.

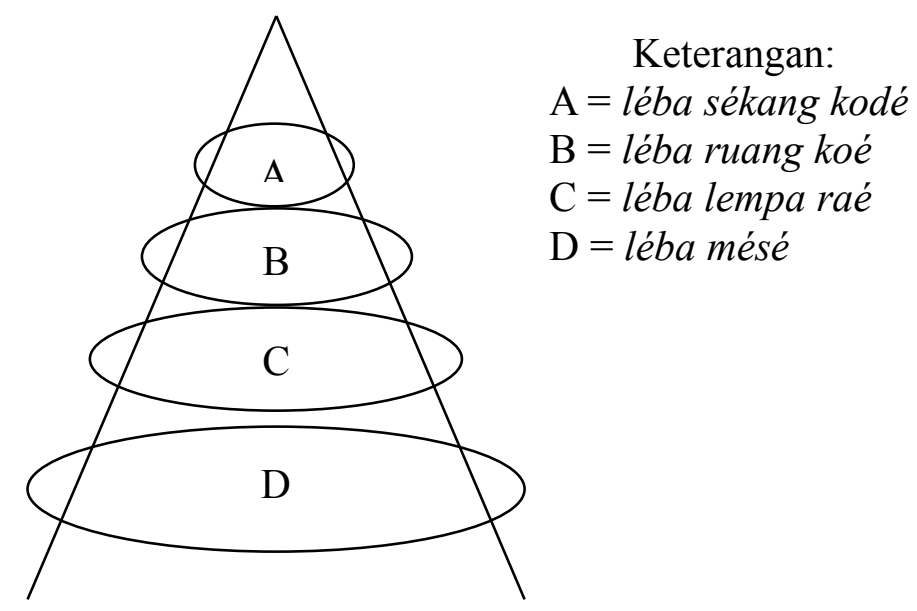

Gambar 5. Sketsa atap mbaru niang pada bagian léba yang menyerupai lingkaran

Berdasarkan hasil penelitian dapat dilihat pada Gambar 6, bahwa perpotongan dari dua buah gélak wéngké léok dengan dua buah tonggor menyerupai bangun datar trapesium.

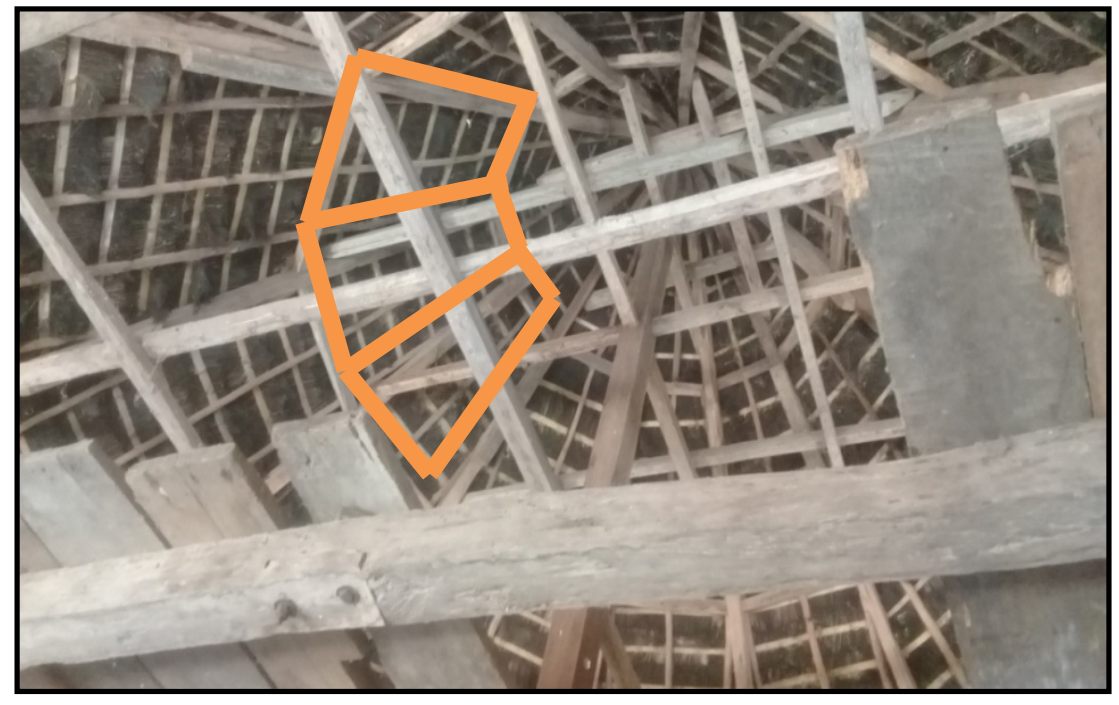

Gambar 6. Jaring atap mbaru niang yang menyerupai trapesium

Guru dapat menerapkan pembelajaran kontekstual dengan mengenalkan pada siswa bangun datar yang terdapat dalam kehidupan mereka sehari-hari dan yang sering mereka jumpai dalam kehidupan sehari-hari. Dalam pembelajaran di kelas guru mengarahkan siswa untuk mengamati bentuk jaring-jaring atap mbaru niang dan menemukan bangun 
datar apa saja yang terbentuk dari jaring-jaring atap mbaru niang. Guru dapat menerapkan pembelajaran diluar kelas dengan mengajak siswa mengunjungi rumah adat Manggarai sehingga pembelajaran matematika tidak menjadi pelajaran yang menjenuhkan dengan itu siswa dapat diajak melihat bentuk atap rumah adat Manggarai dan melihat bentuk bangun datar segitiga secara langsung. Dengan melihat secara langsung siswa dapat lebih memahami perbedaan bentuk-bentuk bangun datar dengan melihat sendiri benda konkret yang menyerupai bangun datar. Selain itu siswa lebih mudah mengingat materi yang diberikan karena mereka memiliki pengalaman dalam belajar dengan melihat secara langsung benda-benda yang berkaitan dengan pelajaran matematika dalam kelas. Dengan ini siswa dengan mudah mengenal macam-macam bangun datar dan merasa bahwa matematika itu ada dalam kehidupan sehari-hari.

b. Konsep jarak

Jarak merupakan ruang atau sela yang dapat menghubungkan antara dua lokasi ataupun dua objek yang dihitung melalui hitungan panjang dan waktu. Dalam memasang wunut pada atap mbaru niang dimulai dari bagian bawah atap, pada satu lepar yaitu lepar kedua dari bagian bawah atap dipasang wunut dengan lebar 3-5 pagat sehingga menutupi lepar dibagian bawahnya karena lebar wunut 3 atau 4 pagat maka jarak atar lepar yaitu \pm 2 pagat maka satu wunut bisa menutupi 2 lepar. Setelah itu dilanjutkan lagi dengan pemasangan wunut pada lepar ke 4 dari bagian bawah atap sehingga menutupi lepar ke 3 dan menutupi bagian atas wunut yang telah dipasang sebelumnya sehingga terlihat seperti saling tindih pada ujung wunut. Pemasangan wunut biasanya berlapis sampai lapis 4 sampai atap benar-benar tertutup dan tidak terlihat celah sehingga bisa menahan hujan dan panas matahari, seperti tampak pada Gambar 7.
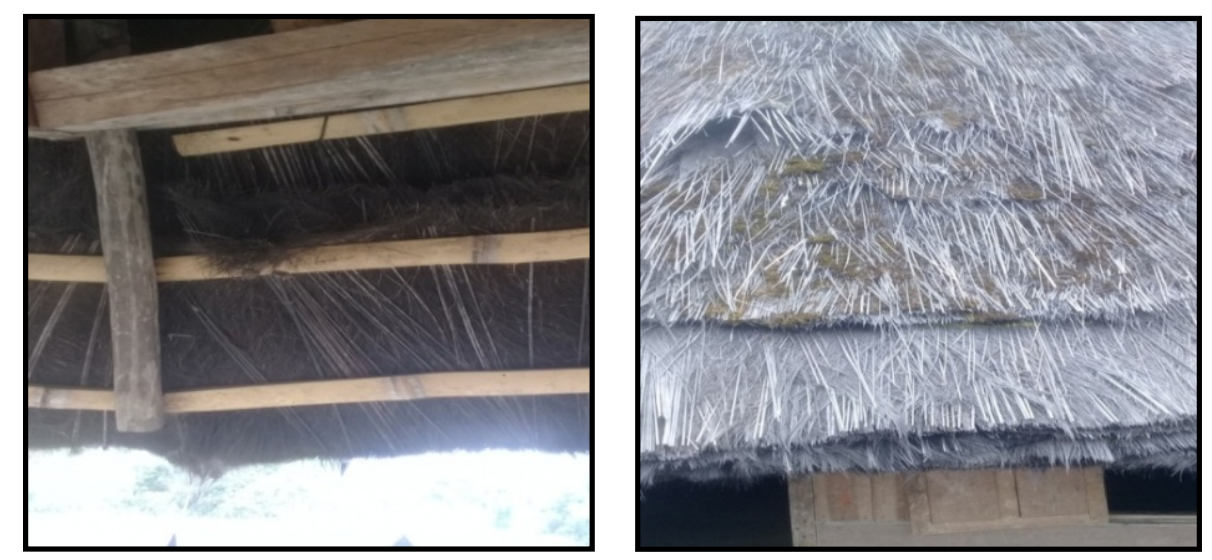

Gambar 7. Wunut pada atap mbaru niang 
Dari proses pemasangan wunut pada atap mbaru niang tersebut maka kita dapat melihat adanya jarak pemasangan antar lepar yang mengikuti lebar wunut karena lepar akan menyangga wunut yang terpasang tersebut.Materi yang terkait dengan konsep jarak yaitu SD kelas I, KD 3.8 mengenal dan menentukan panjang dan berat dengan satuan tidak baku menggunakan benda/ situasi konkret

c. Konsep sejajar, berpotongan dan saling tegak lurus

Postulat Euclidean Paralel menyatakan bahwa dua garis $l$ dan $m$ dikatakan parallel jika tidak terdapat titik $P$ sedemikian sehingga $P$ terletak pada $l$ dan $m$ (Venema, 2012). Lebih lanjut Venema (2012) menjelaskan bahwa jika $l$ dan $m$ adalah dua buah garis berbeda yang tidak parallel maka terdapat tepat satu titik $P$ sedemikian sehingga $P$ terletak pada $l$ dan $m$.

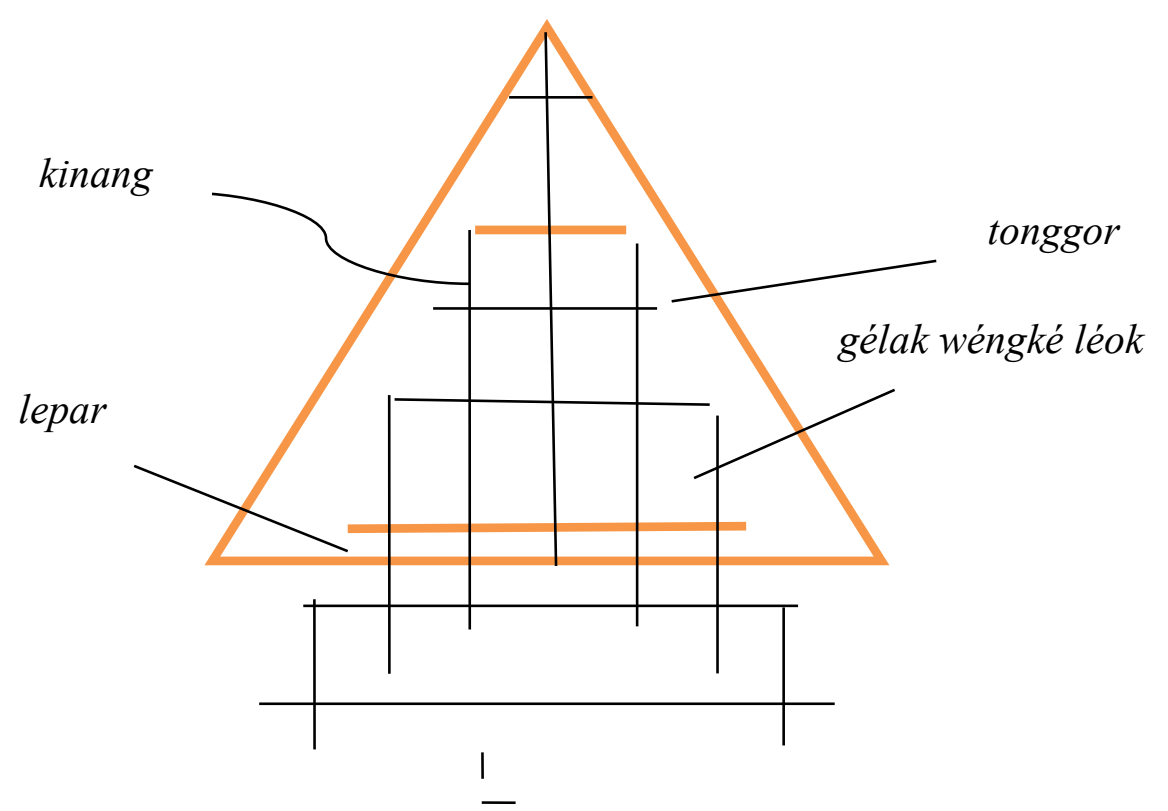

Gambar 8. Ilustrasi sketsa atap mbaru niang

Berdasarkan hasil penelitian, berlaku hubungan sejajar antara kayu lepar yang satu dan lainnya juga antara lepar dan gélak wéngké léok seperti terlihat pada Gambar 8. Selain itu berlaku juga hubungan saling berpotongan antara kedua tonggor saling berpotongan pada ujung atas atap, tonggor dan lepar ataupun tonggor dan gélak wéngké léok juga antara kinang dan lepar atau kinang dan gélak wéngké léok. Pada kinang dan lepar atau kinang dan gélak wéngké léok berpotongan dan saling tegak lurus.Materi yang terkait yaitu pada SD kelas IV 
KD 3.10 Menjelaskan hubungan antar garis (sejajar, berpotongan, berhimpit) menggunakan model konkret. Guru dapat mengajak siswa mengunjungi mbaru niang dan melihat bentuk kerangka atap yang mana kayu-kayu pada atap mbaru niang dapat dipandang sebagai garis dan melihat kedudukan kayu-kayu pada kerangka atap tersebut ada yang saling berpotongan, saling sejajar juga tegak lurus sehingga lebih mudah bagi guru untuk menjelaskan pada siswa konsep hubungan antar garis. Siswa pun dapat melihat secara langsung berupa benda konkret sehingga dapat lebih mudah mengerti dan memahami materi hubungan atar garis.

\section{d. Konsep bangun ruang limas}

A pyramid is defined as "a polyhedron obtained by connecting each vertex of a polygon to a single point outside the plane of the polygon; the sloping sides of a pyramid are therefore triangles (Unlu \& Horzum, 2018). Dengan kata lain limas adalah polihedron yang diperoleh dengan menghubungkan setiap simpul poligon ke satu titik di luar bidang poligon; sisi miring dari piramida adalah segitiga. Ciri-ciri limas: (1) limas memiliki satu sisi alas dan tidak memiliki sisi atas (tutup); (2) titik pucak dan titik sudut sisi alas dihubungkan oleh rusuk tegak; (3) semua sisi tegak limas berbentuk segitiga.

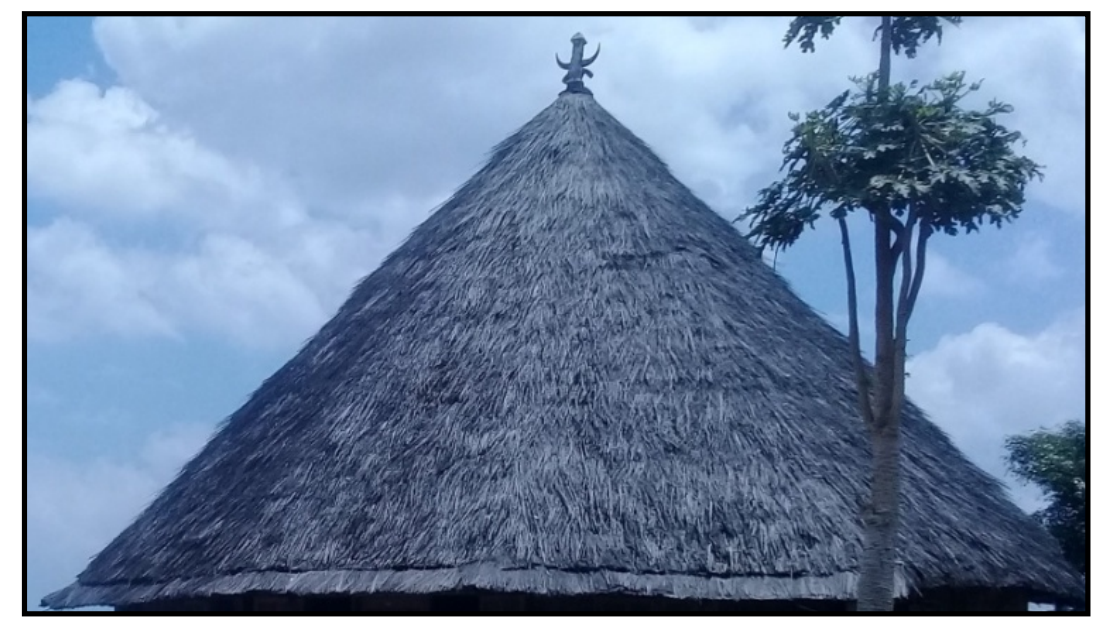

Gambar 9. Atap mbaru niang

Berdasarkan hasil penelitian bentuk atap mbaru niang menyerupai limas dengan alas berbentuk lingkaran, seperti tampak pada Gambar 9. Tinggi limas merupakan tinggi siri wuwung, titik puncak pada mbaru niang dipasang mangka dengan tanduk kerbau. Dapat kita lihat pada atap mbaru niang berlaku sifat limas yang pertama yaitu:

1) Limas memiliki satu sisi alas dan tidak memiliki sisi atas (tutup) juga dapat terlihat pada bentuk atap mbaru niang yang tidak memiliki sisi atas dan memiliki sisi alas 
yang berbentuk lingkaran.

2) Titik pucak dan titik sudut sisi alas dihubungkan oleh rusuk tegak juga berlaku pada mbaru niang yang manatitik puncak mbaru niang yaitu titik dimana dipasang mangka dan tanduk kerbau dan rusuk tegak yang menghubungkan titik puncak dan titik sudut sisi alas yaitu siri wuwung pada mbaru niang.

3) Semua sisi tegak limas berbentuk segitiga dapat terlihat pada kerangka atap mbaru niang membentuk segitiga dari setiap tonggor yang terpasang. Sisi tegak berbentuk seperti segitiga bila dilihat dari bagian dalam atap rumah adat (kerangka atap rumah adat). Namun bila dilihat dari luar, atap rumah adat itu menyerupai kerucut (seperti pada Gambar 9).

Materi yang terkait yaitu materi kelas IX KD 3.7 Membuat generalisasi luas permukaan dan volume berbagai bangun ruang sisi lengkung (tabung, kerucut, dan bola). Guru dapat mengajak siswa atau dapat memberikan tugas kelompok pada siswa berupa proyek untuk menghitung luas permukaan bangun ruang (limas dengan alas berbentuk lingkaran) dengan mengunjungi rumah adat terdekat.

Siswa dapat melakukan wawancara pada warga atau orang yang dapat membantu siswa untuk mengetahui ukuran-ukuran kayu-kayu pada kerangka mbaru niang seperti tinggi atap, panjang diameter alas atap mbaru niang dan lainnya yang dapat membantu siswa menjawab pertanyaan mengenai luas permukaan limas. Keterbatasan lingkungan tempat belajar siswa yang tidak didukung oleh fasilitas dan kegiatan-kegiatan ekstrakulikuler seperti kurangnya buku- buku matematika, bimbingan belajar, organisasi di sekolah dan lain sebagainya dapat ditunjang oleh kekayaan budaya yang dapat bermanfaat sebagai jembatan pengetahuan (Gunur et al., 2018). Di saat yang sama, keluhuran budaya lokal, nilai-nilai spiritual dan makna di baliknya dapat diwariskan kepada generasi muda.

\section{SIMPULAN}

Konsep matematika yang digunakan dalam pembuatan atap rumah adat Manggarai adalah bentuk bulat yang menyerupai lingkaran dan ujung atap yang mengerucut sebagai bentuk atap rumah adatnya. Hal ini didasarkan pada kebiasaan dan kepercayaan masyarakat Manggarai bahwa mereka dalam merundingkan sesuatu selalu berkumpul 
dalam forum lonto léok (duduk melingkar) dan perasaan bahwa mereka ca nai ca tuka (sehati dan sepikiran). Dalam menentukan panjang dan jarak kayu pada proses pembuatan atap mbaru niang juga masyarakat melakukan aktifitas menghitung dan membilang. Masyarakat Manggarai menghitung menggunakan alat ukur yang tidak baku yaitu dengan menggunakan jari dan tangan. Adapun satuan ukur yang digunakan antara lain pagat, ciku dan depa.

Konsep matematika lain yang terdapat dalam pembuatan atap rumah adat Manggarai adalah konsep bangun datar diantaranya bangun datar yang terbentuk dari jaring-jaring atap mbaru niang yaitu trapesium, segitiga dan lingkaran. Konsep jarak pada saat menentukan letak kayu-kayu yang dipasang sebagai jaring-jaring atap. Konsep dua buah garis yang sejajar, berpotongan dan saling tegak lurus. Konsep bangun ruang limas di mana limas yang terbentuk dari atap rumah adat Manggarai yaitu limas yang memiliki alas berbentuk lingkaran.

\section{DAFTAR RUJUKAN}

Abdullah, A. S. (2017). Ethnomathematics in Perspective Of Sundanese. Journal on Mathematics Education, 8(1), 1-16.

Achor, E. E., Imoko, B. I., \& Uloko, E. S. (2009). Effect of ethnomathematics teaching approach on senior secondary students' achievement and retention in locus. Educational Research and Reviews, 4(8), 385-390.

Aikpitanyi, L. A., \& Eraikhuemen, L. (2017). Mathematics Teachers' Use of Ethnomathematics Approach in Mathematics Teaching in Edo State. Journal of Education and Practice, 8(4), 34-38.

Barton, W. D. (1996). Ethnomathematics : Exploring Cultural Diversity in Mathematics. The University of Auckland,.

Biembengut, M. S. (2016). Mathematical modelling, problem solving, project and ethnomathematics : Confluent points. CERME 9 - Ninth Congress of the European Society for Research in Mathematics Education, 816-820.

D'Ambrosio, U. (1985). Ethnomathematics and its Place in the History and Pedagogy of Mathematics. Learning of Mathematics, 5(1), 44-48.

D'Ambrosio, U. (2001). What is Ethnomathematics, and How Can It Help Children in Schools? Teaching Children Mathematics, 7(6), 308-311. 
Fujiati, I., \& Mastur, Z. (2014). Keefektifan Model Pogil Berbantuan Alat Peraga Berbasis Etnomatika terhadap Kemampuan Komunikasi Matematis. Unnes Journal of Mathematics Education, 3(3), 174-180.

Gall, M. D., Gall, J. P., \& Borg, W. R. (2007). Educational Research : An Introduction. In Pearson Education Inc (Vol. 1).

Gunur, B., Parinters Makur, A., \& Hendrice Ramda, A. (2018). Hubungan Antara Kemampuan Numerik dengan Kemampuan Pemecahan Masalah Matematis Siswa di Pedesaan. MaPan, 6(2), 148-160.

Indrawati, Y. (2015). Etnomatematika Pada Proses Jual Beli Yang Dilakukan Masyarakat Osing Di Pasar Tradisional Sebagai Bahan Pembelajaran Aritmetika [Universitas Jember].

Makur, A. P., Sutam, I., Gunur, B., \& Rampung, B. (2019). Lingko: Interweaving Manggarai Culture, and Mathematics. Journal of Physics: Conference Series, $1315(1), 012006$.

Mumu, J., \& Aninam, P. A. (2018). Analisis Konteks Asal Budaya Papua dalam Pendidikan Matematika Realistik. Journal of Honai Math, 1(1), 24-33.

Puspadewi, K. R., \& Putra, I. G. N. N. (2014). Etnomatematika di Balik Kerajinan Anyaman Bali, Jurnal Matematika, 4(2), 80-89.

Risdiyanti, I., \& Prahmana, R. C. I. (2018). Etnomatematika: Eksplorasi dalam Permainan Tradisional Jawa. Journal of Medives, 2(1), 1-11.

Rosa, M., \& Orey, D. C. (2013). Ethnomodeling as a Research Theoretical Framework on Ethnomathematics and Mathematical Modeling. Journal of Urban Mathematics Education, 6(2), 62-80.

Safitri, D. (2015). Eksplorasi Konsep Matematika pada Permainan Masyarakat Melayu Sambas [Universitas Tanjungpura].

Unlu, M., \& Horzum, T. (2018). Mathematics Teacher Candidates 'Definitions of Prism and Pyramid. International Journal of Research in Education and Science, 4(2), $670-685$.

Venema, G. A. (2012). Foundations of Geometry. Pearson Education, Inc. 
Journal of Honai Math, Vol. 3, No. 1, pp. 57-76, April 2018

Muliani, Makur, Kurnila, \& Sutam. Rumah Adat Manggarai Dalam Perspektif Matematika 